\title{
Morphological Pattern of Ovarian Tumour : Experience in a Tertiary Level Hospital
}

\author{
M AHMED $^{\mathrm{a}}, \mathrm{N} \mathrm{AFROZE}^{\mathrm{b}}$, M SABIHA $^{\mathrm{c}}$
}

Summary:

Background: Ovarian tumor is a common type of gynecological neoplasm and accounts for 15-25\% of all gynecological malignancies. It is associated with high mortality and an accurate histological diagnosis is essential for management of patient.

Objective: The study was performed to find out the morphological pattern, nature and age distribution of ovarian tumour in our hospital.

Material and methods: It was a prospective study,conducted in the Department of Histopathology and Cytopathology, BIRDEM General Hospital, Dhaka for a period of two years from Jan 2014 to Dec 2015. This study included 186 cases of ovarian tumors sent in the Department of Pathology for histopathological evaluation. Non-neoplastic lesions and tumour-like conditions were excluded from the study. Histological diagnosis, age and laterality of ovary were recorded. Morphological pattern, nature and age distribution of ovarian neoplasms were calculated.

Result: $84.95 \%$ cases of ovarian tumour were benign, $1.61 \%$ cases were borderline and $13.44 \%$ cases were malignant.

Introduction:

Ovarian tumor is a common type of gynecological neoplasm in female. A wide variety of tumor arises in ovary from its different cell lineages and fall into benign, borderline or malignant categories. ${ }^{1}$ Ovarian cancer accounts for $15-25 \%$ of all gynecological malignancies, but is associated with the highest mortality rate (50\%) in

a. Dr. Mousumi Ahmed, Associate Professor, Department of Pathology, BIRDEM General Hospital.

b. Prof. Dr. Nazma Afroze, Professor and Head Department of Pathology, BIRDEM General Hospital.

c. Dr. Mahjabin Sabiha, Medical Officer, Department of Pathology, BIRDEM General Hospital.

Address of Correspondence: Dr. Mousumi Ahmed, Associate Professor, Department of Pathology, BIRDEM General Hospital, Cell Phone: 01714003820. E-mail: mousumi7406@gmail.com

Received: 20 Oct. 2016

Accepted: 28 Sept. 2017
Surface epithelial tumour was the commonest type of tumour (61.83\%), according to the histogenesis, followed by germ cell tumour. Benign serous tumour was the most common type of benign tumor (37.98\% cases), followed by mature cystic teratoma (33.55\% cases). Serous cystadenocarcinoma was the most common type of malignant tumour (36.0\%), followed by endometrioid carcinoma (28.0\%). Benign tumours were more frequent in all age group. The incidence of malignant ovarian tumour increased with age and was most frequent in $>50$ years age group.

Benign tumours were commonly cystic, whereas malignant tumours were commonly solid and cystic. $11.23 \%$ cases of ovarian tumours were bilateral.

Conclusion: Benign ovarian neoplasms were more common than malignant ones and benign serous tumour was the commonest type of benign neoplasm whereas serous cystdenocarcinoma was the commonest type of malignant neoplasm. The pattern and age distribution of ovarian tumour of our study were quite similar with other studies with some variation.

(J Bangladesh Coll Phys Surg 2018; 36: 5-10)

this group. The poor survival is due to the fact that they do not clinically manifest early and approximately $60-70 \%$ of the neoplasm present as either stage III or stage IV. ${ }^{2,3}$

As there are no screening tests or tumor markers and low cytological accuracy in predominantly cystic neoplasm, histopathology plays a key role in detection of type and nature of ovarian tumour. ${ }^{4} \mathrm{An}$ accurate histological diagnosis is also crucial for management of patient.

Aim of the study was to find out the morphological pattern, nature and age distribution of ovarian tumour in our hospital.

Material and methods:

This was a prospective study, conducted in the Department of Histopathology and Cytopathology, BIRDEM General Hospital, Dhaka for a period of two years from Jan 2014 to Dec 2015. This study included 
186 cases of ovarian tumors sent in the Department of Pathology for histopathological evaluation. Nonneoplastic lesion and tumour-like conditions were excluded from the study. Age and laterality of ovarian specimens were recorded. The nature of specimens were frozen section biopsy sample, simple oophorectomy, unilateral / bilateral salpingo-oophorectomy and hysterectomy with unilateral / bilateral salpingooophorectomy. Gross examinations were done following the guideline described by standard textbook of surgical pathology. Paraffin blocks were made; Hematoxylin and Eosin (H\&E) stained histological slides were prepared and examined under microscope. The tumors were classified according to the World Health Organization classification of ovarian tumors. The study was approved by hospital ethical committee based on best practice of ethics in medicine and in concordance with the principals of Helsinki declaration and written consent was taken from every patient. Reported results and relevant data were recorded in SPSS data collection sheet and statistical analysis was carried out using SPSS version 17.

For descriptive purposes, patients were divided into three age groups, as follows: 0-19 years, 20-50 years and more than 50 years. Different morphological types of benign serous tumour such as serous cystadenoma, papillary serous cystadenoma, serous cystadenofibroma, papillary serous cystadenofibroma were grouped as benign serous tumour. Similarly different morphological variants of benign mucinous tumours were grouped as benign mucinous tumour. Thecomas, fibromas and thecofibromas were grouped altogether as fibromas/ thecomas. Morphological pattern, nature and age distribution of ovarian tumours were calculated

\section{Result:}

A total 186 cases of ovarian tumours were found. Age ranges from 9 years to 70 years, median age was 50 years. Among these 158 cases $(84.95 \%)$ were benign, 3 cases $(1.61 \%)$ were borderline and 25 cases $(13.44 \%)$ were malignant.

Surface epithelial tumour was the commonest type of tumour $(61.83 \%)$ according to the histogenesis followed by germ cell tumour (table I and II).

Benign serous tumour was the most common type of benign tumor and seen in $60(37.98 \%)$ cases, followed by mature cystic teratoma (table III).

Serous cystadenocarcinoma was the most common type of malignant tumour (36.0\%) followed by endometrioid carcinoma. All malignant cases, that occurred below 20 years of age were germ cell in origin (table IV).

Both benign and malignant ovarian tumours were found in all age groups. Median ages for benign, borderline and malignant tumour were 44years, 20.5years and 47.5 years respectively. Overall, ovarian tumour was most prevalent in 20- 50 years age group (table II).

Table-I

\begin{tabular}{lccccc}
\multicolumn{5}{c}{ Pattern of ovarian tumour according to histogenesis $(n=186)$} \\
Histogenesis of tumour & Benign & Boderline & Malignant & Total & Percentage \\
\hline Surface epithelial Tumour & 93 & 3 & 19 & 115 & 61.83 \\
Germ cell tumour & 53 & - & 4 & 57 & 30.64 \\
Sex cord stromal Tumour & 12 & - & - & 12 & 6.45 \\
Metastatic & - & - & 2 & 2 & 1.08 \\
\hline
\end{tabular}

Table-II

\begin{tabular}{lccccc}
\multicolumn{5}{c}{ Frequency of ovarian neoplasm in different age group } \\
Age(years) & $\begin{array}{c}\text { Surface epithelial } \\
\text { tumour }\end{array}$ & $\begin{array}{c}\text { Germ cell } \\
\text { tumour }\end{array}$ & $\begin{array}{c}\text { Sex cord/stromal } \\
\text { tumour }\end{array}$ & $\begin{array}{c}\text { Metastatic } \\
\text { tumour }\end{array}$ & Total \\
\hline $0-19$ & 4 & 10 & - & - & $14(7.52 \%)$ \\
$20-50$ & 72 & 40 & 10 & - & $122(65.60 \%)$ \\
$>50$ & 39 & 7 & 2 & 2 & $50(26.88 \%)$ \\
\hline Total & $115(61.83 \%)$ & $57(31.64 \%)$ & $12(6.54 \%)$ & $2(1.08 \%)$ & $186(100 \%)$ \\
\hline
\end{tabular}


Incidence of malignant ovarian tumour increased with age and was most frequent in $>50$ years age group (table III). However, in all age groups benign tumours were more frequent than malignant neoplasm. Only three cases of borderline tumour were found. Two cases occurred in 20- 50 years of age and one case occurred in 0-20 years of age.

Consistency of tumours was cystic in 145 cases (77.96\%), solid in 18 cases $(9.68 \%)$ and solid and cystic in 23 cases $(12.36 \%)$. Consistency of benign tumours was commonly cystic whereas malignant tumours were commonly solid and cystic (table V).

Among 186 cases, information regarding laterality of tumours was found in 89 cases. Of these 10 (11.23\%) cases were bilateral, $42(47.19 \%)$ cases involved the right side and $37(41.57 \%$ ) cases involved the left side of ovary.

Table-III

Frequency of benign tumour in different age group

\begin{tabular}{lcccc} 
Diagnosis & $0-19$ years & $20-50$ years & $>51$ years & Total \\
\hline Benign serous tumour & 1 & 37 & 22 & $60(37.98 \%)$ \\
Mature cystic teratoma & 7 & 39 & 7 & $53(33.55 \%)$ \\
Benign mucinous tumour & 1 & 21 & 3 & $25(15.82 \%)$ \\
Fibromas/thecomas & - & 10 & 2 & $12(7.59 \%)$ \\
Brenner tumour & - & 2 & 2 & $4(2.53 \%)$ \\
Mixed surface epithelial tumour & - & 2 & 2 & $4(2.53 \%)$ \\
\hline Total & $9(5.70 \%)$ & $111(70.25)$ & $38(24.05 \%)$ & $158(100 \%)$ \\
\hline
\end{tabular}

Table-IV

Frequency of malignant tumour in different age group

\begin{tabular}{lcccc} 
Diagnosis & $0-19$ years & $20-50$ years & $>51$ years & Total \\
\hline Serous cystadenocarcinoma & - & 3 & 6 & $9(36.0 \%)$ \\
Endometrioid carcinoma & - & 3 & 4 & $7(28.0 \%)$ \\
Mucinous cystadenocarcinoma & - & 3 & - & $3(12.0 \%)$ \\
Immature teratoma & 3 & 1 & - & $4(16.0 \%)$ \\
Metastatic carcinoma & - & - & 2 & $2(8.0 \%)$ \\
\hline Total & $3(12.0 \%)$ & $10(40.0 \%)$ & $12(48.0 \%)$ & $25(100 \%)$ \\
\hline
\end{tabular}

Table-V

\begin{tabular}{lcccc}
\multicolumn{5}{c}{ Consistency pattern of ovarian tumour } \\
Consistency & Benign & Boderline & Malignant & Total \\
\hline Cystic & 142 & 3 & 0 & $145(77.96 \%)$ \\
Solid & 15 & - & 3 & $18(9.68 \%)$ \\
Solid and cystic & 1 & - & 22 & $23(12.36 \%)$ \\
\hline Total & 158 & 3 & 25 & $186(100 \%)$ \\
\hline
\end{tabular}




\section{Table-VI}

Relative frequencies of five commonest benign ovarian tumour in our study with other studies.

\begin{tabular}{lcccccc} 
Name of tumour & \multicolumn{6}{c}{ Percentage (\%) of cases in different studies } \\
\cline { 2 - 7 } & Tejeswini & Vaidya & Sharma & Ahmad & Abdullah & Present \\
& et al. & et al. & et al. & et al. & et al. & study. \\
& $(2013$, & $(2014$, & $(2014$, & $(2000$, & $(2012$, & \\
& India) & Nepal) & India) & Pakistan) & Saudi Arabia) & \\
\hline Benign serous tumour & 64.98 & 24.57 & 44.05 & 38.93 & 44.60 & 37.97 \\
Mature cystic teratoma & 21.66 & 14.33 & 32.14 & 35.17 & 33.80 & 33.54 \\
Benign mucinous tumour & 8.30 & 57.00 & 14.29 & 18.18 & 13.60 & 15.82 \\
Fibroma & 1.82 & 1.02 & - & 2.96 & 6.47 & 6.32 \\
Brenner & 0.92 & 0.34 & - & 0.79 & - & 2.53 \\
\hline
\end{tabular}

\section{Table-VII}

Relative frequencies of five commonest malignant ovarian tumour in our study with other studies.

Name of tumour

Percentage $(\%)$ of cases in different studies

\begin{tabular}{|c|c|c|c|c|c|c|}
\hline & $\begin{array}{c}\text { Tejeswini } \\
\text { et al. } \\
\text { (2013, } \\
\text { India) }\end{array}$ & $\begin{array}{l}\text { Vaidya } \\
\text { et al. } \\
\text { (2014, } \\
\text { Nepal) }\end{array}$ & $\begin{array}{l}\text { Sharma } \\
\text { et al. } \\
\text { (2014, } \\
\text { India) }\end{array}$ & $\begin{array}{c}\text { Ahmad } \\
\text { et al. } \\
\text { (2000, } \\
\text { Pakistan) }\end{array}$ & $\begin{array}{c}\text { Abdullah } \\
\text { et al. } \\
\text { (2012, } \\
\text { Saudi Arabia) }\end{array}$ & $\begin{array}{l}\text { Present } \\
\text { study. }\end{array}$ \\
\hline Serous cystadenocarcinoma & 49.18 & 29.82 & 16.67 & 30.65 & 33.30 & 36.00 \\
\hline Endomertioid carcinoma & 3.28 & 8.77 & 38.89 & 15.76 & - & 28.00 \\
\hline Mucinous cystadenocarcinoma & 21.30 & 7.01 & 11.11 & 12.03 & 15.40 & 12.00 \\
\hline Immature teratoma & 1.64 & 15.79 & 5.56 & 1.71 & 2.38 & 16.00 \\
\hline Metastatic carcinoma & 4.92 & 10.52 & 11.11 & 0.20 & 15.50 & 8.00 \\
\hline
\end{tabular}

\section{Discussion:}

Ovarian tumour arises from different cell lineage. ${ }^{1}$ In Pakistan, a study conducted by Ahmed et al. ${ }^{5}$ found surface epithelial tumour were most common type of ovarian tumour $(63.50 \%)$, followed by germ cell tumours $(27.13 \%)$ and sex cord-stromal tumours(5.84\%). In India, a study conducted by Sharma et al. ${ }^{6}$ found surface epithelial tumours comprised $60.78 \%$, germ cell tumours $30.39 \%$ and sex cordstromal tumours $5.88 \%$ of ovarian tumour. In Saudi Arabia, Abdullah ${ }^{7}$ found $61.0 \%$ of ovarian tumours were surface epithelial in origin, $28.0 \%$ were germ cell in origin, $7.6 \%$ were sex cord stromal tumour and 3.4\% were metastatic. Whereas in Nepal, Vaidya ${ }^{8}$ found germ cell tumours were most common $(51.52 \%)$, followed by surface epithelial tumour (43.53\%) and sex cord stromal tumour(3.30\%). In Nigeria and Africa, germ cell tumours were the commonest ovarian neoplasm followed by surface epithelial tumours. ${ }^{9}$ In the western countries and in Japan, surface epithelial tumors were the most common tumour and account for 50 to $55 \%$ and 46 to $52 \%$ of ovarian tumour respectively. ${ }^{8}$ In present study, we found surface epithelial tumours were commonest tumour according to histogenesis (60.75\%) followed by germ cell tumour $(31.72 \%)$ and sex -cord stromal tumour $(6.54 \%)$. Our findings were quite similar with the studies conducted in India, Pakistan and Saudi Arabia but differ from the studies conducted in Nepal and Africa, where germ cell tumours were most common.

The ovarian tumour is diagnosed as benign, borderline or malignant depending on the presence of predominant cell type, pattern of growth, amount of fibrous stroma and cellular atypia with invasiveness. ${ }^{1}$ In India, in a study it was found that $78.4 \%$ of ovarian tumours were benign, $20.6 \%$ were malignant and $0.98 \%$ cases were 
borderline. ${ }^{6}$ In the same country, Gupta et al. ${ }^{10}$ reported ovarian tumours were $72.9 \%$ benign, $4.1 \%$ borderline and $22.9 \%$ malignant. In Saudi Arabia, Abdullah ${ }^{7}$ found $61.0 \%$ of ovarian tumours were benign, $5.2 \%$ were borderline and $22 \%$ were malignant. In Nepal, Vaidya ${ }^{8}$ found $80.72 \%$ of ovarian tumour were benign, $3.58 \%$ were borderline while $15.70 \%$ were malignant. In Pakistan Ahmad et al. ${ }^{5}$ found 59.18\% ovarian tumour were benign, $3.27 \%$ were borderline and $37.54 \%$ were malignant. However, in another study in Pakistan, Siddiqui et al. ${ }^{11}$ found $79 \%$ ovarian tumours were benign and $17.8 \%$ were malignant. In India, Mondol et al. ${ }^{12}$ found benign tumours were most common (63.1\%), followed by malignant (29.6\%) and borderline (7.3\%). In Nigeria, $80.3 \%$ of the ovarian neoplasms were found benign while malignant ovarian tumours constituted $19.7 \%$ of cases. ${ }^{9}$ In present study, it was found that $84.95 \%$ of ovarian tumours were benign, $1.61 \%$ cases were borderline and $13.44 \%$ were malignant. Findings of our study were quite similar with study conducted in Nepal. Frequency of malignant ovarian neoplasm of our study was much lower than the some other studies. However, all studies found benign ovarian tumours were more frequent than malignant ones.

Like the studies in India and Pakistan, present study found benign serous tumour was most common type of benign ovarian neoplasm, followed by mature cystic teratoma and benign mucinous tumours ( table 6) .However, some studies conducted in Nepal, Nigeria and North America found mature cystic teratoma was the most common type of benign neoplasm. ${ }^{8,9}$

Serous cystadenocarcinoma was the most common type of malignant neoplasm. It was found as the most common malignant neoplasm in studies conducted in India, Pakistan and Saudi Arabia also. ${ }^{5,67,11}$ However, in Nepal, mucinous cystadenocarcinoma was found as the most common malignant tumour. ${ }^{8}$ Frequency of other common malignant neoplasms also varies slightly in different studies (table 7).

Similar to present study, other study also showed ovarian tumour had a wide range of age distributions. A study conducted in Indian subcontinent found overall median age for ovarian tumour was 33 years and the median age for benign, borderline and malignant tumour was 32,47 and 40 years respectively. ${ }^{4}$ However, in our study overall median age for ovarian tumour was 50 years and median age of its different types also vary slightly. Similar to the findings of Abdulla et al. ${ }^{7}$, our study also found that the frequency of malignant ovarian neoplasm increases with age, it was most prevalent in more than 50 years of age and all the malignant neoplasm that occurred below 20 years of age was germ cell in origin. Like other studies, 5, 6, 7,8,11,13 our study also found benign tumors were more common than malignant tumours in all age groups.

Present study showed cystic ovarian neoplasm was commonest followed by solid and cystic than predominantly solid. Vaidya et al. ${ }^{8}$ found $45.09 \%$ ovarian tumors were cystic, $41.17 \%$ were solid and cystic and $13.74 \%$ were predominantly solid. Frequency of solid and cystic neoplasm was more than present study.

Bilaterality was found in $8.86 \%$ cases and $11.29 \%$ cases in studies conducted by Vaidya et al. ${ }^{8}$ and Sharma et al. ${ }^{6}$ respectively. Similar to these, present study also found $11.23 \%$ tumours were bilateral. However, incidence of bilaterality was found much less in studies by Tejeswini et al. ${ }^{4}$ and Misra et al. ${ }^{13}$. They found $5.40 \%$ and $4.52 \%$ of ovarian neoplasms were bilateral respectively.

\section{Conclusion:}

In this study it was found that benign ovarian neoplasms were more common than malignant ones. The most common type of benign ovarian neoplasm was benign serous tumour and the most common type of malignant neoplasm was serous cystdenocarcinoma. The pattern and age distribution of ovarian tumours of our study were quite similar with other studies with some variation. This study may be useful in future for further study of ovarian neoplasm in Bangladesh.

\section{References:}

1. Rosai J. Female reproductive system-Ovary. In Rosai J, ed. Rosai and Ackermann's Surgical Pathology. Edinburgh: Mosby Elsevier, 2004:1553-1635.

2. Benson RC. Diagnosis and treatment. Current Obstet Gynaecol 1976;1:236.

3. Ramzy I. Essentials of Gynecologic and Obstetric Pathology. Appleton Century Crofts: Connecticut1983: 231.

4. Tejeswini V, Reddy S, Premalatha P, Vahini G. Study of morphological patterns of ovarian neoplasms.IOSRjournal 2013;10(6 ):11-16

5. Ahmad Z, Kayani N, Hasan SH, Muzaffar S, Gill MS. Determination of Histological Pattern of Ovarian Neoplasm. JPMA 2000; 50(12): 416-419. 
6. Sharma I, Sharma U, Dutta. Pathology of ovarin tumour- a hospital based study. International journal of medical science and clinical invention 2014;1(6) :284-286.

7. Abdullah LS and Bondagji NS. Histopathological pattern of ovarian neoplasms and their age distribution in western region of Saudi Arabia. Saudi Med J 2012; 33(1): 61-65.

8. Vaidya S, Sharma P, KC S, Vaidya SA. Spectrum of ovarian tumour in a referral hospital in Nepal. Journal of Pathology Nepal. 2014;1 4: 539-543.

9. Onyiaorah IV, Anunobi CC, Banjo AA, Nwankwo KC.Histopathological patterns of ovarian tumours seen in Lagos University Teaching Hospital: a ten year retrospective study. Nig Q J Hosp Med 2011;21(2):114-8.
10. Gupta N, Bisht D, Agarwal AK, Sharma VK. Retrospective and prospective study of ovarian tumours and tumour like lesions. Indian J Pathol Microbiol 2007;50:525-7

11. Siddiqui RB, Sharma B, Khan MI. Morphological pattern of ovarian neoplasm in different age groups. A center based study. P JMHS 2015:9(4):1139-1143

12. Mondal SK, Banyopadhyay R, Nag DR, Roychowdhury S, Mondal PK, Sinha SK. Histological pattern, bilaterality and clinical evaluation of 957 ovarian neoplasm: A 10-year study in a tertiary hospital of eastern India. J Can Res Ther 2011;7:433-7

13. Misra RK, Sharma SP, Gupta V, Gaur R, Mishra SD. Pattern of ovarian neoplasms in Eastern U.P. Jorunal of OBG1991; $241-246$ 